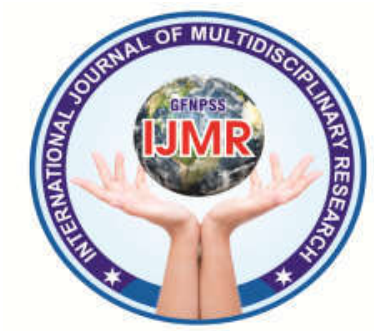

Review Article

\title{
THE NEGATIVE IMPACT OF MOBILE PHONE ON STUDENTS \& SOCIETY
}

\section{VARSHA UPADHYAY}

\author{
Lecturer, Mahatma Gandhi Nursing College, Jaipur
}

(Mahatma Gandhi University of Medical Sciences \& Technology, Sitapura, Jaipur

\section{Corresponding Email: varshau1991@gmail.com}

\section{BACKGROUND}

Now a day's mobile phone usability increased in students and society. There are many benefits of using mobile phone along with excessive use of mobile phone become stress in our life. Currently use of mobile phone more concern in students and society. Various efforts have been made through research to identify increased use of mobile phone.

At present, mobile phones are being used everywhere. The mobile radiations may give harmful effects, will give major problems also in males' infertility, Ear problems, Immunity system, Eye vision problems, high blood pressure, tiredness, stress, sleep distribution, impaired concentration, memory and finally gets DNA problems. ${ }^{1}$

Key words: Impact, mobile phone, student and society.

\begin{tabular}{ccc}
\hline Received & Accepted & Available online \\
\hline $05 / 06 / 2021$ & $17 / 06 / 2021$ & $30 / 06 / 2021$ \\
\hline
\end{tabular}

\section{INTRODUCTION}

Due to advancement in technology increasing mental illness and management for psychological wellbeing conditions also enhanced due to increase use of mobile phone on large scale. Impact of mobile phone admission in the hospital may increase. During this time mobile phone are the essential of every one in day to day life. Those Person are used excessive mobile phone has reached up to $89 \%$, more than enlarge over a 6 -year period; more than $70 \%$ use social media per day. Analysis found that $86 \%$ of students have mobile phone with increased Use of social media communication with their growing age. Its 


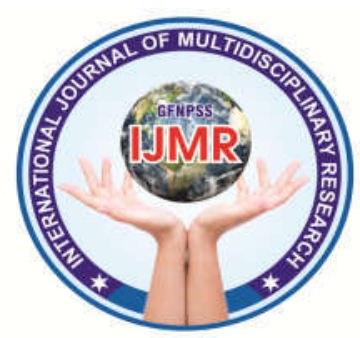

evidence that due to Mobile phone and social media use with mental distress and suicide occurs.

Increase interaction of advanced mobile phone usability than in other individual in society. An survey of middle- and high school students revealed that the increase number of suicidal thought and ideas higher among those who had more cyber uses. ${ }^{2}$

\section{MOBILE PHONE \& RISKS}

\section{ASSOCIATED WITH STUDENTS}

Due to more risk of mobile phone academic institute wants to integrate mobile devices in their environment. As institutes decide the transformation of integrating mobile devices into their education along with policy. The use of technology instrument increases the vulnerabilities to the security of their systems. Educational practices in the classroom should emphasis the correct use of these devices to minimize risks to the system. $^{3}$

\section{The human factor may lead to more risks} in the classroom, as outlined below:

$>$ Cheating can take place. Students can send messages or data for answers to

$>$ questions during the examination. Students may cheat by hide formulas and

documentation files within mobile phone to access the content during exams.

$>$ Students may provide threats by using devices.

Mobile phone may make noises during the class.

> Individual may take improper photos and videos using the mobile devices.

The excessive use of mobile phone by students may increased the problem.

\section{NEGATIVE EFFECTS OF MOBILE PHONES ON SOCIETY}

But more usability of smart phone has a negative impact student and society. Spending too much time on a mobile screen affects children's development and education, social interaction, and family relationships. $^{4}$

\section{Effects of Mobile Phones on Children} and Teenagers- many harmful effects of mobile phones on children include excessively being engrossed on mobile screen for hours. It impacts psychology and development of a child. The utilize of smart phone by school going students hindering the parental relationship.

Make use of the internet on mobile phone reveals to improper behaviors in 


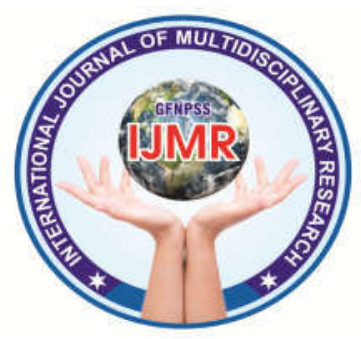

the students and they May seen unusual content in the mobile phones.

This can develop a negative effect on the psychology of the children, causing to irrelevant behavior.

\section{Effects of Cell phones on Education -} Students who use mobile phones excessively perform poorly in class as compared to those who don't. students who used mobile phone during the class they may received less information about topic and may lead an negative impact on performance.

More use of mobile phones leads to headache, irritability, and anger shown in various research studies.

Social relationships also adversely affect by excessive use of smart phone. School going children who consume excessive time on their mobile phones become socially isolated. They tend to spend time browsing the net or watching movies instead of interacting with others.

\section{Effects of Mobile Phone on Crime -} Many people can't afford mobile phones due to rise in their prices, thereby they resort to the mobile phone stealing/ snatching. Moreover, mobile phones have contributed heavily towards stalking and harassment cases.

\section{Impact of Mobile Phone on Health -} According to The International Agency for Research on cancer, radiation from mobile phones is possibly carcinogenic. Additionally, it's been found that excessive usage of mobile phone leads to poor sleep patterns and efficiency, turning into insomnia.

\section{Effects of Mobile Phone on Social Life}

- The biggest victim of use of smartphones is our relationships. We prefer texting to talking face to face. Mobile phones have replaced treasured personal moments with family and friends. This is causing broken relationships. One drifts away from reality and connects with real people via virtual means like Whatsapp, Facebook etc.

\section{Effects of Cellphones on}

Relationships- We look at our phones a lot during our conversations even with our loved ones and people close to us, giving clear message that phones have become more important. This leaves the 


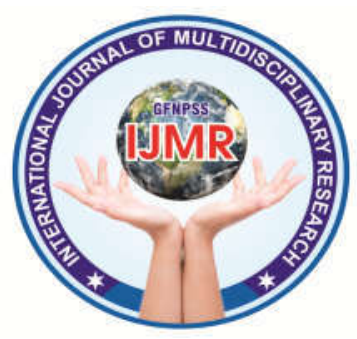

other partner feeling ignored and

unimportant. Human beings are

experiencing emotional disconnect for

high usage of mobile phones. It also

causes mood swings, behavioral changes

etc. resulting in fragmented relations and

often divorce.

7. Driving and mobile phone - one of the most dangerous effects of mobile phone is on driving. Using a mobile phone while driving leads to a lot of accidents since we lose focus. A mobile phone can be a major distraction while doing any activity where you need Total focus and attention.

\section{DISADVANTAGES OF MOBILE PHONES}

1. Waste of time: Time is money and money is time. Do not waste your time due to cell phones, do not use it much, always try to less use of mobile phones, and save your time and spent it on good ways.

2. Cause of diseases: Mobile phones can be a cause of skin diseases, cancer and eye problems etc. and many other disorders.
3. Radiation: It has been found out that radiation emission from mobiles and signal from nearby mobile tower can be very harmful to a human being leading to cancer and impotency in males etc.

\section{REFERENCE}

I. G. SasiPriya, A. JothiPriya*, R. Gayatri Devi. Impacts of excessive mobile phone usage on adult.

II. Prof. Giriraj Prasad Soni ,Omprakash Swami: Mobile phone uses and its effects on mental health SDES international journal of interdisciplinary research volume 2 issue 2 march-April 2021:164-167.

III. https://www.du.ae/personal/helpandsupp ort/mobile/besafe/mobile-and-portabledevices-risks-new/cyber-safety-forstudents

IV. https://www.addictiontips.net/phoneaddiction/negative-effects-of-mobilephones-on-society/ 